\title{
Portfolio Assessment Implementation in Clinical Year of Community Medicine Module: Students' Perspective
}

\author{
Fika Ekayanti, Risahmawati, Marita Fadhilah \\ Department of Community Medicine, Faculty of Medicine and Health Sciences \\ Syarif Hidayatullah State Islamic University \\ Jakarta, Indonesia \\ fikaekayanti@uinjkt.ac.id
}

\begin{abstract}
Portfolio has been used as summative assessment in many fields of study. Since 2010, clinical community medicine module has used portfolio to assess students. Nine portfolios were assigned to students within 5 weeks length module. This study aimed to identify the correlation of students' perspective for using portfolio and their portfolio scores. The data was collected by questionnaires from 46 students after completing module in November 2016. Students were asked about their satisfaction of using portfolio, then correlated to their portfolio scores. The reasons and suggestion for ideal portfolios were identified. Analysis was done by SPSS 20 using Rank Spearman correlation test. Students felt that creating portfolios were not comfortable. Most students $(36 / 78.3 \%)$ felt that the portfolio was not appropriate as their summative assessment. They preferred less portfolios, $30(63 \%)$ students requested to decrease portfolios to $3-5,28.3 \%$ to $6-8$ and only $8.7 \%$ to $<3$. There was no significant correlation between students' satisfaction of using portfolio to their portfolios score $(p=0.262)$, while there was significant correlation between students' score to the number of portfolios to be submitted ( $p=0.017 ; r=0.349$ ). Reasons for decreasing number of portfolios were inadequate time and many other tasks to be finished. Students in UIN Jakarta haven't used to retelling their experiences and reflecting them in writing as perceived in many students who were not used to portfolios. Doing portfolios need lots of work and time-consuming. Having lesser number of portfolios to be submitted would encourage students to create portfolios. Building familiarization, time management and good motivation for creating portfolios were important to successful portfolios. There was no significant correlation between students' satisfaction to their scores. Students should be encouraged to get comfortable in creating portfolios for the benefit as lifelong learning tool. Motivation to write and reflect should be nurtured to improve students' portfolio satisfaction and commitment.
\end{abstract}

Keywords-assessment, reflective writing, satisfaction of using portfolio

\section{INTRODUCTION}

Community medicine module in clinical year or also known as clerkship year of medical doctor is a compulsory for students as it represents workplace learning in primary care services [1]. In Indonesia, all students graduate as medical doctors that will serve in primary care services. The experience of workplace learning in community medicine is essential for students' future professional career. The learning outcomes were based on Standard of Competence for Indonesian Medical Doctor that was acknowledged by Indonesian Medical Council [2].

Community medicine module used the concept of Community Oriented Medical Education (COME) that would learn to practice as a professional doctor in primary care services, able and willing to serve their community, respond and deal effectively to the needs of community concern. The students should have commitment to medicine's clinical and social problems, specific skills to practice in the community, and learn on how to play a role in health service management directly or in the real time for the community [3]. This learning strategy has also supported solution for clerkship learning to Flexner concept of spiral curriculum that moving practice based learning from inpatient to ambulatory settings, from hospitals to community settings and into longitudinal integrated clinical attachments [4].

The concern of workplace-based learning for medical doctors was that patient encounter with the students mostly unobserved by the faculty members, so that there was little opportunity for assessment of basic clinical skills and furthermore, less of feedback for improving students' performance [5]. Based on strategies of workplace-based assessment, there were many instruments that can be exercised for the students including direct observation; structured observation and feedback of clinical performance, such as mini CEX; review on work products; multi-source feedback; learning portfolios; logbooks; and encounter cards [6].

In community medicine module, the students were assessed by two summative workplace-based assessment strategies; those were mini CEX and portfolios. From all rotations that the students should encounter in the clinical years, mini CEX assessment was implemented in some other module rotations. However, portfolio assessment was not the case that other department rotations would be accustomed. In medical doctor study program of State Islamic University Jakarta, Indonesia, there was only department of community medicine that chose portfolios as one of strategies for summative assessment [7]. The students were introduced for the first time to portfolio assessment in the community medicine module of the clinical phase rotation program. 
Portfolio has been used as an instrument of assessment in medical education over the last 2 decades [8]. It is a bundle of personal report that consists of description on professional experiences and reflections on action with systematic and logical analysis that is supported by references and documentation as evidence of the action [8-11]. Portfolio in the principles of experiential learning has put reflection as the central point of learning process. It links the students to embrace their professional experience with the knowledge and skills they have learnt along the medical education [11]. As an assessment of clinical performance that comprises combination and integration of knowledge, clinical skills, attitude and professionalism as doctor competences, portfolio is suitable to provide judgment of clinical performance. Portfolio allows to evaluate students' various competences and assess the process of learning [12].

With the strategy of using portfolio as summative assessment in workplace-based learning, the students' perspective about portfolio is needed to identify issues of creating portfolio among the students and identify ways to encourage students to be motivated on creating their portfolios. Although portfolio has high face validity, its drawback as summative assessment is in the issue of reliability related to content specificity and rater issues [11]. Input from students would propose better performance for portfolio assessment implementation. It expected to increase the reliability as summative assessment in the module.

\section{METHOD}

The study is a quantitative study that used analytical approach of correlation within variables observed. The data was collected with cross-sectional method that was taken from the total number of 46 students who were joined the community medicine module in one rotation. It was held in October $19^{\text {th }}$ to November $16^{\text {th }}, 2016$.

\section{A. Context}

Community medicine module in the clinical phase at Medical Doctor Study Program of State Islamic University of Syarif Hidayatullah Jakarta was implemented in community health center (Pusat Kesehatan Masyarakat - Puskesmas) and community health clinic of the university as the learning site for students' practice. Nine community health centers were selected by the health office of Tangerang district that each of them received a group of 5-6 students, and 2 community health clinics. Students were under supervised by the preceptor of the site. The preceptor is the doctor who works and has been appointed by the head of the community health center to be the supervisor for the students.

At the beginning of the community medicine module, there were 2 days refreshment and briefing for the students before they practiced in the community health center. The portfolio assessment was explained and simulated during the time. At the third day of the module, the students visited the community health center. They were asked to plan their schedule along their time in community health center and approved by their preceptor. They spent 17 days in community health center, 2 days in the community health clinic and 3 days in campus to discuss the progress of portfolios with faculty members as the tutor, and report students' group tasks in community health center. The group tasks included the community diagnosis or program evaluation report, case study with family folder and home visit, and boarding school health program. Lastly the final week of the module, students were asked to present all their group tasks in front of the preceptors and faculty members, and assessed by the faculty members as assessor of portfolios.

\section{B. Portfolio assessment procedure}

Webb has divided portfolio into 4 models. There are shopping trolley, toast rack, cake mix, and spinal column [13]. The portfolio in this community medicine module is designed like cake mix model. The students should create 9 portfolios for the summative assessment that are consist of 4 internal activities that they can choose among ambulatory care, mother and child program, infection diseases eradication program, nutrition program, tuberculosis program, or pharmacy; 3 external activities that the community health center program has implemented, such as posyandu or integrated service station, posbindu or integrated care station, home visit, public health promotion program, school health program, community health survey, mobile health center, etc.; mini CEX report and boarding school health promotion program (table 1). Each portfolio the students created should be blended with evidence on activities and reflective commentaries with analytical criteria.

The preceptor in community health center and faculty members in campus, were the students' guide for portfolio progresses. The faculty members who were in charge as tutors on the module met the students once a week to discuss students' portfolios and give their comment on it as the students' feedback. The students were targeted to show at least 2 portfolios for each meeting, while the preceptors were depended on their eligible time along the students' activities in the community health center. The summative results were taken from average score of inter-rater that consisted of preceptor, tutor and assessor. With the assessor, the students should explain their portfolios report by face-to-face assessment at the end of the module.

The form of rubric criteria for scoring the portfolio was comprised the clinical management of patient's problems with family approach, community problems management, quality of evidence provided by the students, reflection skill, skill to receive feedback, and quality of professionalism achievement. The last 3 items of criteria were the general students' performance when they interact with the tutor, preceptor or assessor, while the other 3 items were about the quality of report.

\section{Data analysis}

The data was collected by questionnaires. At the end of the module, students were asked to fill in questionnaires to get their perspective about portfolio assessment. The questions were about whether students were satisfied or not for using portfolio as one of their summative assessment in the community medicine module, their reason for the answers, and their input on the ideal number of portfolio that they felt suitable to be submitted for the module. The questionnaire results then correlated the students' satisfaction to the 
students' portfolios scores, afterward, it analyzed the correlation between the number of portfolios to be submitted to their portfolios scores. The data was analyzed by SPSS 20 using Rank Spearman correlation test.

\section{RESULTS}

Portfolio has been used in community medicine module as assessment instrument since the first batch of clinical year students. It was used due to its main function that has discretion for providing feedback to students in workplace setting [11]. There is a significant gap between practice in theory and reality. One of the most critical lacks in workplace learning of current medical education practice is less feedback based on observation of the students' performance [5].

Since the beginning of portfolio assessment was implemented, there has been once modified in 2013 with nine portfolios collected by students. This study would direct future modification of portfolio implementation of the module. With 46 students as total respondents, there were $18(39 \%)$ male students, and $28(61 \%)$ female students.

The students stated that portfolio was not appropriate as their summative assessment. There were 36 (78.3\%) students felt dissatisfaction for creating portfolios, while only 10 $(21.7 \%)$ were accepted portfolio as their assessment instrument. The reasons for students' dissatisfaction were that $33(71.7 \%)$ students thought the number of portfolios to be submitted were too many within the tight schedule of the module. They needed much time for writing reflection with the supported references. Two (4.3\%) students felt that there the time to do portfolios was inadequate; because they should do other group tasks beside portfolio that they should be made. While, the rest of $11(23.9 \%)$ students felt that portfolio assessment was suitable. It showed that there was $1(2.2 \%)$ student that stated portfolio was not appropriate, however he felt that the number of portfolios to be submitted was acceptable.

The students were also asked about the suitable number of portfolios that they would be willingly submitted as the summative assessment. Their answers were mostly 3-5 portfolios (63\% of students' answer), followed by $6-8$ portfolios $(28.3 \%)$, while the rest of students' answers were less than 3 portfolios $(8.7 \%)$.

The Spearman's rho test for correlation showed that there was no significant correlation between students' perspective for portfolio as summative assessment to their portfolio scores $(p=0.262)$, while the number of portfolios to be submitted was significantly correlated to students' scores $(p=0.017)$ with adequate correlation $(\mathrm{r}=0.349)$. The correlation between students' perspective of portfolio as summative assessment to the number of portfolio to be submitted was also significant $(\mathrm{p}=0.01)$ with adequate correlation $(\mathrm{r}=0.377)$.

\section{DISCUSSION}

Many literatures have stated that portfolio is the best instrument for assessment that provided sufficient feedback to students' performance and understanding [5]. Portfolio as learning assignments was reported as effective tool as those received reviews from peers and tutor as feedback, so that those have increased students' skill performance in skills training session of problem-based learning [14].

Feedback was essential for students in their clinical setting. It can be provided by agents, whether teacher, peer, self, etc., that contained information regarding aspects of students' performance or understanding. The main purpose of providing feedback to students was to reduce discrepancy between current practices or understandings and desired practices or understandings [15]. The information would influence students to confirm, increase, overwrite, or restructure it in their memories.

There were three principal questions that should be addressed to the learners in giving feedback. First question was "where am I going?" To trigger students to answer the question, there has to be clear learning goals of the module. Secondly was "how am I going?" It required clear indicator and effective feedback to students. The last question was "what actions need to be taken to close the gap between actual and desired performance?" This question needed action plan from students to improve their future performance [5]. The format of portfolio in community medicine module has fulfilled those questions that student would get specific feedback from preceptor, tutor and assessor. The portfolio was taken in the field of actual practice situation that the students would encounter; the structure of reflection has been designed for students to express their analysis about the activity process and their plan for improvement (table 1).

The format of rubric in the module has also referred to the four focuses of feedback. Feedback focused on task, process of the task, self-regulation and self as a person (Hattie \& Timperley, 2007). Reflection part of portfolio would generate students to provide internal feedback and cognitive routines while they wrote the portfolio [5]. Feedback would also successful to improve the quality of data performance in students' learning [16].

From perspective of students in the module, they felt that creating portfolio was not comfortable as they stated that portfolio was not suitable as their summative assessment. The crucial skill that the students need to have in creating portfolio is reflective writing skill. Reflective writing is specific writing skill which includes reflection in the context of learning. Reflection in the context of learning is "a generic term for those intellectual and affective activities in which individuals engage to explore their experiences in order to lead to new understandings and appreciations" (Boud, et al, 1985; 19) [17]. Reflection is necesary for effective use of feedback, self regulated and lifelong learning [18]. Boud (1985) has also mentioned that portfolio means a work-book with experiences of learning or life. Portfolio would help students to articulate thoughts and feelings in more concrete with their own words. It helped students to identify feelings and can recall many aspects to be remembered. It is a good instrument for learning about self because it's facility of communicating personal experiences and raised awareness of new knowledge [17].

Students in the module haven't used to retelling their experience and reflecting them in writing. Doing portfolios need a lot of works and take a longer time to finish their portfolios. Having lesser number of portfolios to be submitted 
would encourage students to create portfolios. The students' perspective has been identified in other studies as the disadvantages of portfolio. The acknowledged disadvantages were time consuming, extensive paperwork, difficulties in collecting evidence with many activities in the clinical learning $[8,17,18]$. Therefore, many students who were asked to create portfolios percieved the task as a "burden". However summative assessment was important in maintaining the effectiveness of creating portfolios [10].

Hrisos, Illing and Burford (2008) stated that trainees who believed the portfolio to be a good idea, were reported to have better understanding of its use and more positive perception of an educational benefit than those who thought that portfolios were not worthed. Creating good portfolios, there were several things should be considered [10, 19]:

1. Students should have a proper introduction and mentoring about the objective of portfolio assessment were needed.

2. Students should have a clear guidelines and user friendliness of the structure and number of portfolios due to limited time demands on students and mentors.

3. Students were encouraged to exercise writing skill. The portfolios should be written openly, sincerely, aggressively. Less description of activities were encouraged with more writing on reflection. The writing should flow, uncensored and reflect on the experiences. It should be made as an activity of habituation.

4. Students should be encouraged to have discipline. The time to write should be arranged every week to describe and reflect on the experiences.

5. Students should have good relationship with their mentors. Their learning is affected by clinicians' willingness to engage in supportive dialogue. Promoting an informal, inclusive discourse of workplace learning might enhance clerkship education. This approach should take its place alongside - and perhaps ahead of - the currently dominant discourse of "clinical teaching."

6. Studens should be maintained to have interaction with other students.

Therefore, the future implementation for portfolio should consider to build familiarization and good motivation, and also plan time management in creating portfolio. Those were important aspects to have for creating successful portfolio assessment.

\section{CONCLUSION}

There was no significant correlation between students' portfolio satisfaction to their portfolio scores. The students should be encouraged to get comfortable in creating portfolio for it is useful as lifelong learning tool. The aspects should be considered were to motivate students in writing and reflecting experiences. Those should be nurtured to improve students' portfolio satisfaction and commitment.

\section{ACKNOWLEGMENT}

Thank you for LP2M (Institute of Research and Community Engagement) of UIN Syarif Hidayatullah Jakarta for giving the opportunity to publish this study.

\section{REFERENCES}

[1] Indonesian Medical Council. (2012). Standard of Education for Indonesian Medical Doctor. Jakarta: Indonesian Medical Council.

[2] Indonesian Medical Council. (2012). Standard of Competence of Indonesian Medical Doctor. Jakarta: Indonesian Medical Council.

[3] Hamad, B. (1991). Community-oriented medical education: what is it? Medical Education, 16-22.

[4] Steven, K., Wenger, E., Boshuizen, H., Scherpbier, A., \& Dornan, T. (2014). How clerkship students learn from real patients in practice settings. Academic Medicine, 469-476.

[5] Norcini, J., \& Burch, V. (2007). Workplace-based assessment as an educational tool: AMEE guide no.31. Medical Teacher, 855-871.

[6] Dent, J., Harden, R. M., \& Hunt, D. (2017). A practical guide for medical teachers. United Kingdom: Elsevier Health Sciences.

[7] Community Medicine Department. (2016). Guidance book of community medicine module for clerkship. Jakarta: State Islamic University of Syarif Hidayatullah .

[8] Epstein, R. M. (2007). Assessment in Medical Education . The New England Journal of Medicine, 387-396.

[9] Amin, Z., \& Eng, K. H. (2003). Basics in Medical Education. Singapore: World Scientific.

[10] Driessen, E., Tartwijk, J. v., \& Vleuten, C. v. (2007). Portfolios in medical education: why do they meet with mixed mixed success? A systematic review. Medical Education, 1224-1233.

[11] Pitts, J. (2010). Portfolios, personal development and reflective practice. In T. Swanwick, Understanding medical education: Evidence, theory and practice (pp. 99-110). Oxford: Wiley-Blackwell

[12] Michels, N. R., Driessen, E. W., Van Gaal, L. F., \& De Winter, B. Y. (2009). Portfolio assessment during medical internships: How to obtain a reliable and feasible assessment procedure? Education for Health, 1-9.

[13] Webb, C. (2002). Models of portfolios. Medical Education, 897-898.

[14] Driessen, E., \& Van Der Vleuten, C. (2000). Matching studen assessment to problem-based learning: lessons from experience in a law faculty. Stud Cont Educ, 235-248.

[15] Hattie, J., \& Timperley, H. (2007). The power of feedback. Review of Educational Research, 81-112.

[16] Norcini, J. J. (2005). Current perspectives in assessment: the assessment of performance at work. Medical Education, 880-889.

[17] Boud, D., Keogh, R., \& Walker, D. (1985). Reflection: Turning experience into learning. London: Kogan Page.

[18] Wald, H., Burkan, J., Taylor, J., Anthony, D., \& Reis, S. (2012) Fostering and evaluating reflective capacity in medical education: Developing the REFLECT rubric for assessing reflective writing. Academic Medicine , 41-50.

[19] Hrisos, S., Illing, J., \& Burford, B. (2008). Portfolio learning for foundation doctors early feedback on its use in clinical workplace. Medical Education , 214-223. 
TABLE I. PORTFOLIO ASSESSMENT IMPLEMENTATION IN COMMUNITY MEDICINE MODULE

\begin{tabular}{|c|c|c|}
\hline Item Activities & Structure of portfolio & Rubric criterias \\
\hline $\begin{array}{l}\text { 1. Internal community health center } \\
\text { - General adult policlinic/tuberculosis } \\
\text { program/ infectious diseases } \\
\text { eradication program } \\
\text { - General pediatric policlinic/ nutritional } \\
\text { program } \\
\text { - Child and mother health program } \\
\text { - Pharmacy } \\
\text { 2. } \\
\text { - } \text { Pork) } \\
\text { - Hoblic health promotion/ school health } \\
\text { center/ auxiliary community health } \\
\text { center/ community health survey } \\
\text { Integrated service station/ integrated } \\
\text { care station } \\
\text { Other activities } \\
\text { - Mini-CEX report } \\
\text { Boarding school health promotion } \\
\text { program }\end{array}$ & $\begin{array}{l}\text { 1. Description of activities: } \\
\text { - Name of activity } \\
\text { - Location } \\
\text { - Day and date } \\
\text { - Rescribe of context } \\
\text { management patient problems and } \\
\text { 2. Reflection of activities: } \\
\text { - Name of activity } \\
\text { - Location } \\
\text { Day and date } \\
\text { Reflection on action } \\
\text { 1. Analysis of every steps from history } \\
\text { 2. Iaking to management of patient } \\
\text { Identification of self-improvement } \\
\text { Evidence of activities (pictures, video, } \\
\text { logbook, task report, etc.) }\end{array}$ & $\begin{array}{l}\text { 1. Patient problems management and family } \\
\text { approach related to learning objectives } \\
\text { - Adequate holistic diagnostic } \\
\text { - Pharmacology management } \\
\text { 2. Quality of evidence } \\
\text { - Valid and relevant that focus evidence to } \\
\text { support process and result for learning } \\
\text { objectives } \\
\text { Q. Quality of self-reflection } \\
\text { - Relf-control } \\
\text { - Realize the limitation and self-weak } \\
\text { - Motivation to self-improvement } \\
\text { Response to feedback } \\
\text { - Reaction to feedback } \\
\text { - Awareness to change } \\
\text { Quality of professionalism achievement } \\
\text { - Case variation to support learning } \\
\text { - objectives } \\
\text { Quality of supported references }\end{array}$ \\
\hline
\end{tabular}

